\title{
Effect of Deformation Structure and Annealing Temperature on Corrosion of Ultrafine-Grain Fe-Cr Alloy Prepared by Equal Channel Angular Pressing
}

\author{
Muhammad Rifai $(\mathbb{D}$, Motohiro Yuasa, and Hiroyuki Miyamoto \\ Department of Mechanical Engineering, Doshisha University, Kyoto, Japan \\ Correspondence should be addressed to Muhammad Rifai; rmuhamma@mail.doshisha.ac.jp
}

Received 16 January 2018; Accepted 28 February 2018; Published 11 April 2018

Academic Editor: Michael I. Ojovan

Copyright (C) 2018 Muhammad Rifai et al. This is an open access article distributed under the Creative Commons Attribution License, which permits unrestricted use, distribution, and reproduction in any medium, provided the original work is properly cited.

\begin{abstract}
The effect of the deformation structure and annealing temperature on the corrosion of ultrafine-grain (UFG) Fe-Cr alloys with 8 to $12 \%$ Cr prepared by equal channel angular pressing (ECAP) was investigated with particular emphasis on the stability of the passivation layer. Fe-Cr alloys were processed by ECAP using up to eight passes at $423 \mathrm{~K}$ by the Bc route, followed by annealing at temperatures of 473 to $1173 \mathrm{~K}$ for $1 \mathrm{~h}$. Passivity appeared in all alloys as a result of ECAP, and the stability of the passivation layer was evaluated by anodic polarization measurements in a $1000 \mathrm{~mol} \cdot \mathrm{m}^{-3} \mathrm{NaCl}$ solution. The stability of the passivation layer increased as the degree of deformation became more extensive with successive ECAP passes, and distinct escalation occurred with the formation of a UFG microstructure. In the early stages of annealing at moderate temperatures, the stability of the passivation layer deteriorated, although no visible grain growth occurred, and this effect increased monotonically with increasing annealing temperature. The high degree of stability of the passivation layer on UFG alloys following ECAP can be attributed to the large number of high-angle nonequilibrium grain boundaries, which may lead to $\mathrm{Cr}$ enrichment of the surface region. The deterioration of the passivation layer in the early stages of annealing may be attributed to a change in the grain boundaries to an equilibrium state. The present results show that the superiority of as-ECAPed materials of the Fe-Cr alloy to recovered ones by heat treatment can be achieved with $8-10 \% \mathrm{Cr}$ as observed in $20 \% \mathrm{Cr}$.
\end{abstract}

\section{Introduction}

Metal forming processes such as equal channel angular pressing (ECAP) have received considerable attention over the past two decades as methods for producing ultrafine-grain (UFG) bulk materials for structural applications $[1,2]$. The UFG microstructure produced by severe plastic deformation has a high density of nonequilibrium grain boundaries, which are characterized by excess grain boundary energy and the presence of long-range elastic stress due to a large number of dislocations [3,4]. Annealing at moderate temperatures leads to annihilation and rearrangement of these dislocations and causes the grain boundaries to change to an equilibrium state [4]. Such annealing is likely to impact the corrosion behavior of UFG materials because the grain boundary state influences the mechanical and electrochemical properties. Generally, corrosion resistance in $\mathrm{Fe}-\mathrm{Cr}$ alloys is associated with the formation of a passivation layer. To produce highly corrosion-resistant stainless steel, the minimum $\mathrm{Cr}$ content is $11 \%$, which can be explained in terms of the percolation limit and the selective dissolution of Fe atoms $[5,6]$ in an aqueous corrosive environment.

In previous studies, it was found that UFG Fe-Cr alloys with $20 \%$ Cr processed by ECAP, with a large fraction of nonequilibrium high-angle grain boundaries (HAGBs), exhibited higher corrosion resistance than coarse-grained (CG) material, and this was attributed to enhanced passivation [7-11]. In addition to the chemical composition and the corrosive environment, the deformation structure and the grain boundary state are also expected to play an important role in determining the corrosion resistance. In the present paper, $\mathrm{Fe}-\mathrm{Cr}$ alloys with $\mathrm{Cr}$ contents of 8,10 , and $12 \%$ were processed by ECAP, and their corrosion resistance was evaluated by anodic polarization measurements to determine 

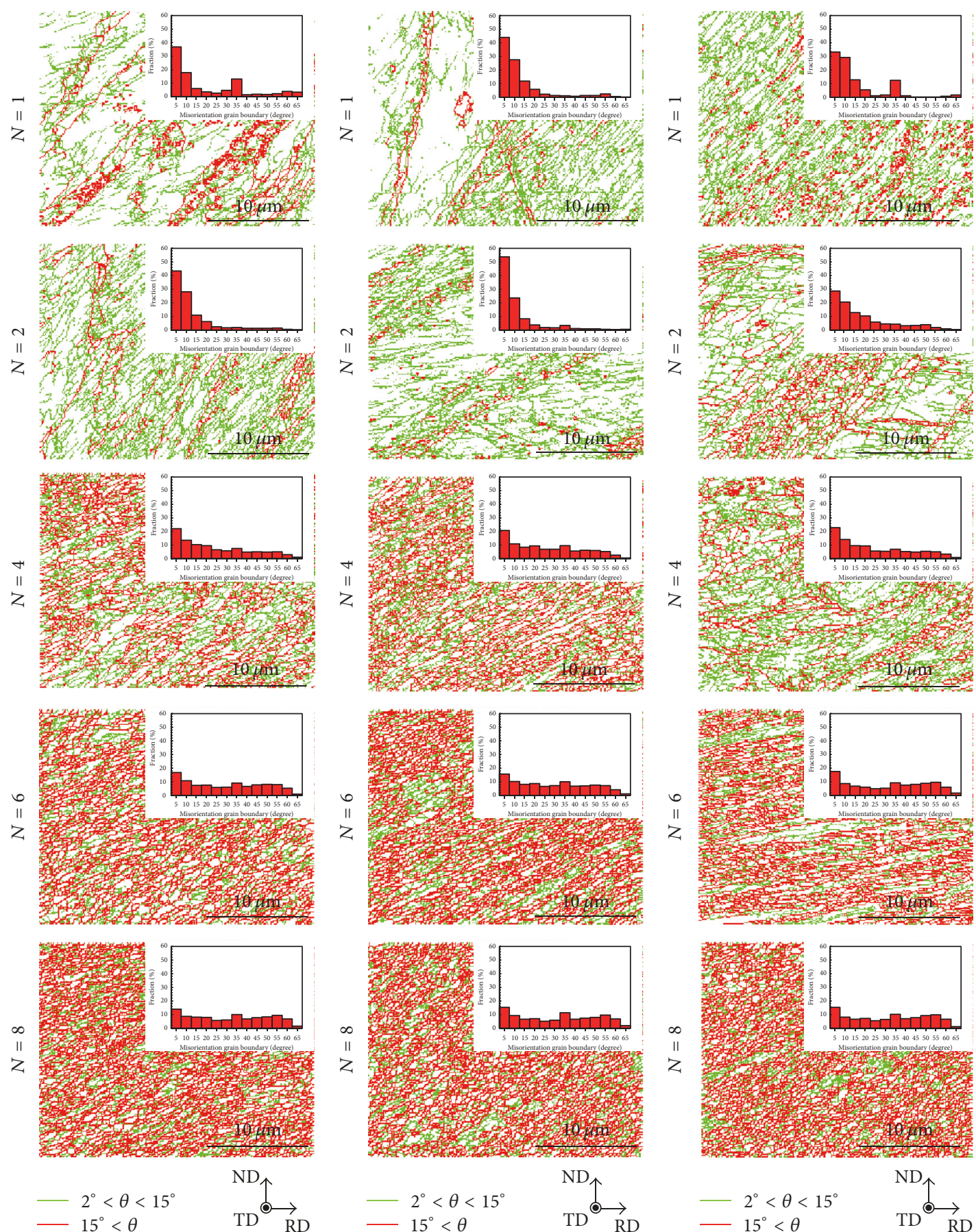

(a)

(b)

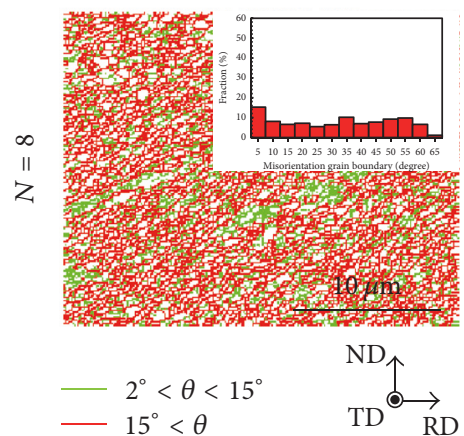

(c)

FIGURE 1: Misorientation maps with the inset figure of distributions for $\mathrm{Fe}-\mathrm{Cr}$ alloy processed by ECAP with (a) $8 \% \mathrm{Cr}$, (b) $10 \% \mathrm{Cr}$, and (c) $12 \% \mathrm{Cr}$.

the stability of the passivation layer. The purposes of the present study were as follows:

(1) To examine the microstructure, hardness, and anodic polarization of UFG Fe-Cr alloys with different $\mathrm{Cr}$ content and the effect of annealing

(2) To characterize the influence of post-ECAP annealing on the critical potential
(3) To investigate the effect of the deformation structure and the annealing temperature on the stability of the passivation layer.

\section{Experimental Procedure}

The material used in the present study was $\mathrm{Fe}-\mathrm{Cr}$ alloy with low carbon and nitrogen contents and $\mathrm{Cr}$ contents 
of 8,10 , and $12 \%$. Each billet was annealed in an argon atmosphere at $1323 \mathrm{~K}$ for $1 \mathrm{~h}$. The initial grain size was about 20-250 $\mu \mathrm{m}$. Specimens with dimensions of $8 \times 8 \times 120 \mathrm{~mm}$ were machined and subjected to ECAP for up to eight passes at $423 \mathrm{~K}$ by the $\mathrm{Bc}$ route, while being lubricated with hightemperature fluorine-based grease. After the ECAP process, the billets were annealed in an infrared furnace (ULVAC MILA5000) from 473 to $1173 \mathrm{~K}$ for $1 \mathrm{~h}$ under a vacuum. An $8 \times 10 \times 2 \mathrm{~mm}$ corrosion test specimen was prepared from a unannealed specimen using a spark-erosion machine [7]. The specimen was coated with epoxy molding to cover the connection between the specimen and cable. The edge area was sealed with premium grade vinyl tape to prevent pitting (crevice) corrosion. The mounted specimen was ground and then polished. Details of the ECAP procedure have been previously published [7]. Field-emission scanning electron microscopy (FE-SEM; JSM 7001F), together with electron backscatter diffraction (EBSD; Oxford Instruments Co.: Model: HKL), was used to observe the grain maps. The EBSD images were processed using INCA ${ }^{\mathrm{TM}}$ (Oxford Instruments Co.). The microstructure was examined by fieldemission transmission electron microscopy (FE-TEM, JEM 2100F). Samples in the form of thin foils were prepared for TEM analysis and subsequently polished using abrasive paper to a thickness of approximately $100 \mu \mathrm{m}$ and and then thinned by twin-jet polishing using a Tenupol 5 instrument (Struers Co., Ltd.) with a solution consisting of $40 \%$ acetic acid, $30 \%$ phosphoric acid, $20 \%$ nitric acid, and 10\% distilled water. Finally, the specimens were polished using an ion beam in a Gatan 691 precision ion polishing system. An acceleration voltage of $200 \mathrm{kV}$ was used for all TEM observations. Further details regarding the microstructure observation process can be found in our prior publication [7].

Microhardness experiments were performed using a Vickers hardness testing machine (Shimadzu HMV-2) under a load, with a $15 \mathrm{~s}$ dwell time, with ten measurements being performed for each sample. X-ray diffraction (XRD) analysis was carried out using a Rigaku SmartLab system with $\mathrm{CuK} \alpha$ radiation, an operating voltage of $40 \mathrm{kV}$, a current of $0.2 \mathrm{~A}$, and a $2 \theta$ angle of $30-130^{\circ}$, under continuous scanning mode. Details concerning the setup for ECAP, XRD, and microhardness testing are available elsewhere [7].

Anodic polarization corrosion tests were carried out in a neutral solution of $1000 \mathrm{~mol} \cdot \mathrm{m}^{-3} \mathrm{NaCl}$ at room temperature by potentiodynamic polarization, using a HZ5000 potentiostat at a scan rate of $20 \mathrm{mV} \cdot \mathrm{min}^{-1}$, a corrosion current, and an $\mathrm{Ag} / \mathrm{AgCl}$ reference electrode. The reference electrode was placed in a saturated $3000 \mathrm{~mol} \cdot \mathrm{m}^{-3} \mathrm{KCl}$ solution (representing a saturated solution). Each sample was immersed in the etchant solution for one hour. The solution was deaerated with argon gas to remove dissolved oxygen. The test process was initialized after the open circuit potential (OCP) of the specimen was stabilized. Details of the corrosion test procedure have also been previously published [7].

Surface analysis was carried out using glow dischargeoptical emission spectroscopy (GD-OES; HORIBA GD Profiler 2); the specimens were first ground and dried in air at room temperature. This technique provides accurate

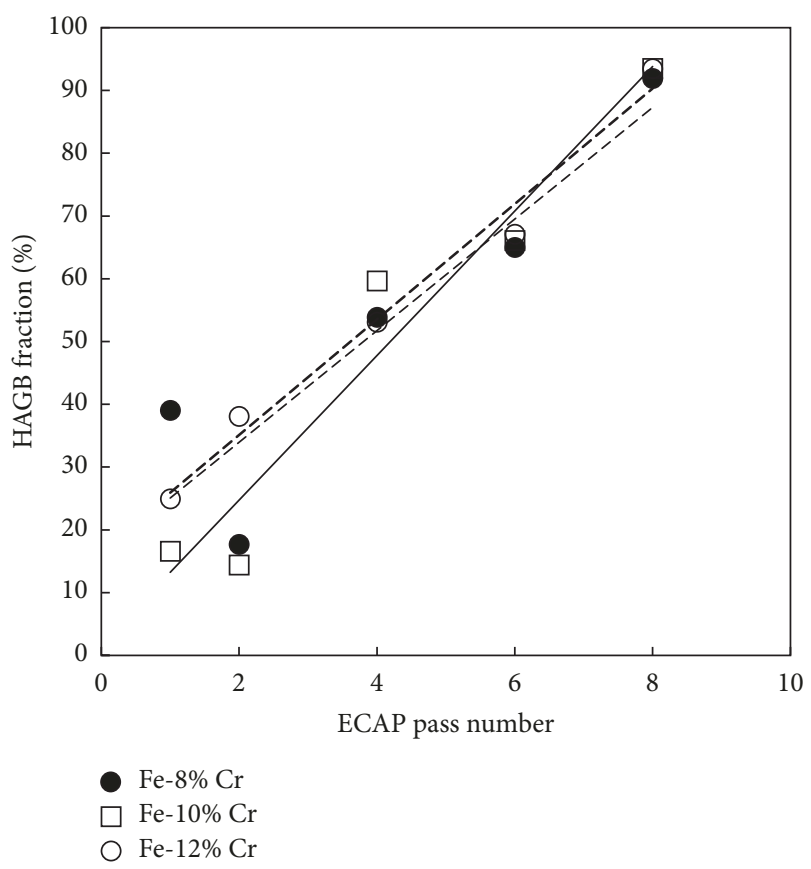

Figure 2: Dependence of HAGB fraction for $\mathrm{Fe}-\mathrm{Cr}$ alloy on a number of ECAP passes.

sputtering sequences, a constant etching rate, excellent sensitivity, and a nanoscale depth resolution. Measurements were performed in synchronous mode using a pulsed RF source at $10 \mathrm{~W}$, with $\varnothing 4 \mathrm{~mm}$ anodes, under an argon atmosphere at $300 \mathrm{~Pa}$.

\section{Results and Discussion}

Microstructural observations using EBSD and TEM revealed the deformation structure and the formation of nonequilibrium grain boundaries from one to eight ECAP passes. Figure 1 shows grain boundary misorientation maps and distributions for $\mathrm{Fe}-\mathrm{Cr}$ alloys following one, two, four, six, and eight ECAP passes in the transverse plane. After one and two passes, low-angle grain boundaries (LAGBs) with misorientations of $2-15^{\circ}$ are common, with only a few HAGBs with higher misorientations. In the distributions shown in the insets, most grains have misorientations of $2-10^{\circ}$. As the number of ECAP passes increases, the distribution shifts to higher misorientation angles, and, following eight passes, there is a large fraction of HAGBs. The change of misorientation to higher values may appear due to local crystal orientation in grains during deformation process by ECAP [11]. This effect has been previously reported for Fe$20 \%$ Cr alloy following ECAP [11].

Figure 2 plots the HAGB fraction against the number of ECAP passes. It can be seen that as the number of passes increases, the HAGB fraction increases rapidly. Regardless of the $\mathrm{Cr}$ content, following eight passes, all specimens had a similar HAGB fraction, indicating a UFG microstructure. This is likely to have an effect on the stability of the passivation layer and the corrosion resistance of the material [11]. 


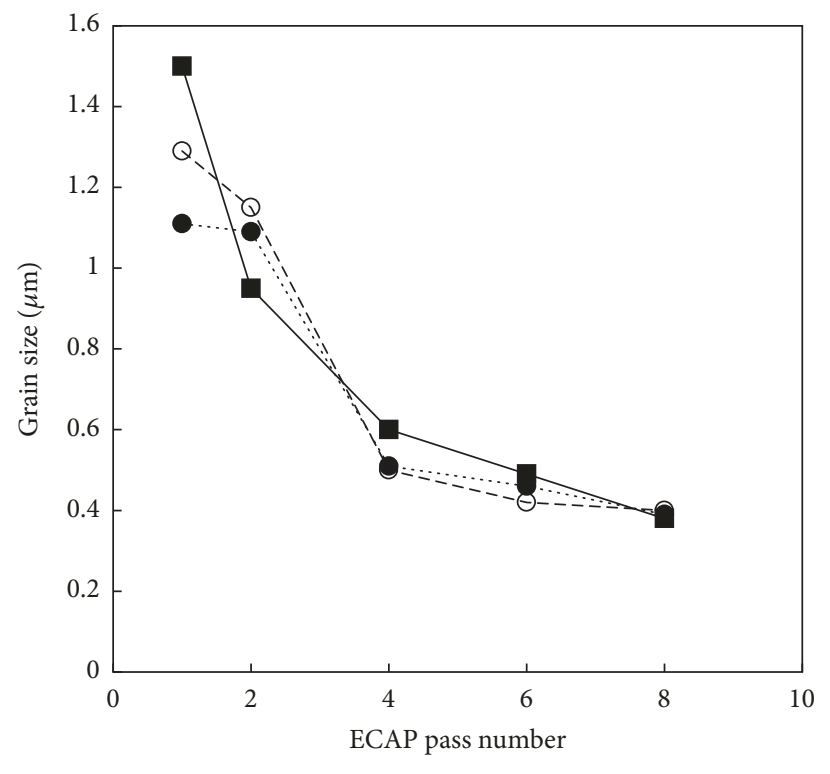

$\mathrm{Fe}-12 \% \mathrm{Cr}$

O $\mathrm{Fe}-10 \% \mathrm{Cr}$

- $\mathrm{Fe}-8 \% \mathrm{Cr}$

FIGURE 3: Dependence of grain size for Fe-Cr alloy on a number of ECAP passes.

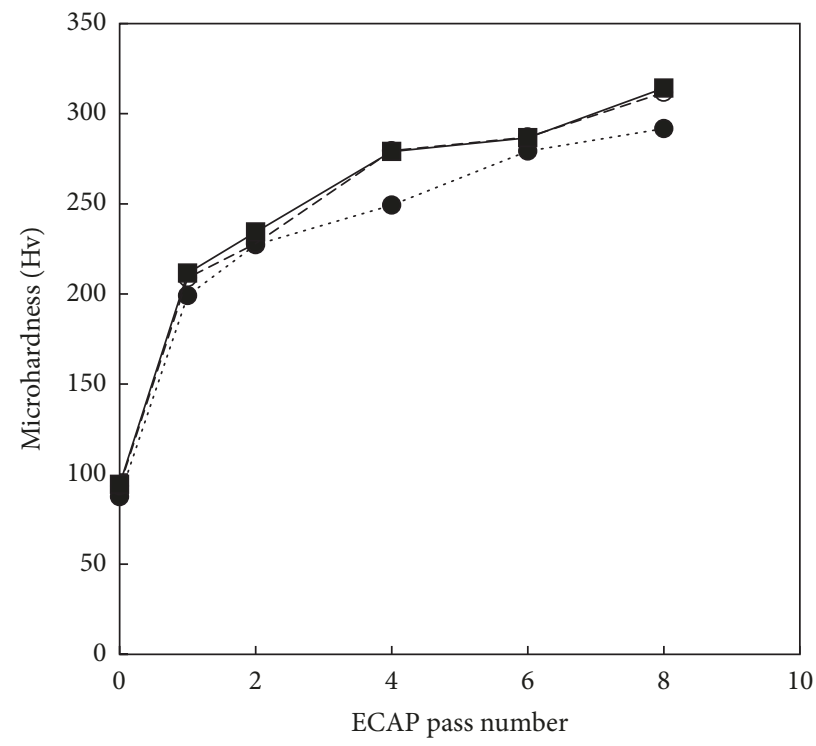

$\mathrm{Fe}-12 \% \mathrm{Cr}$

O $\mathrm{Fe}-10 \% \mathrm{Cr}$

- $\mathrm{Fe}-8 \% \mathrm{Cr}$

FIGURE 4: Dependence of microhardness for Fe-Cr alloy on a number of ECAP passes.

After a single pass, the microstructure is typical of that produced by shear deformation, with shear bands present inside grains. These bands appear in the EBSD maps in Figure 1 as diagonally inclined lines. It is apparent that the grains are finely subdivided into subgrain after one pass [12]. After four passes, the microstructure is a combination of UFGs and submicron grains. After the first pass, the grains are elongated along the shear deformation bands, but they 

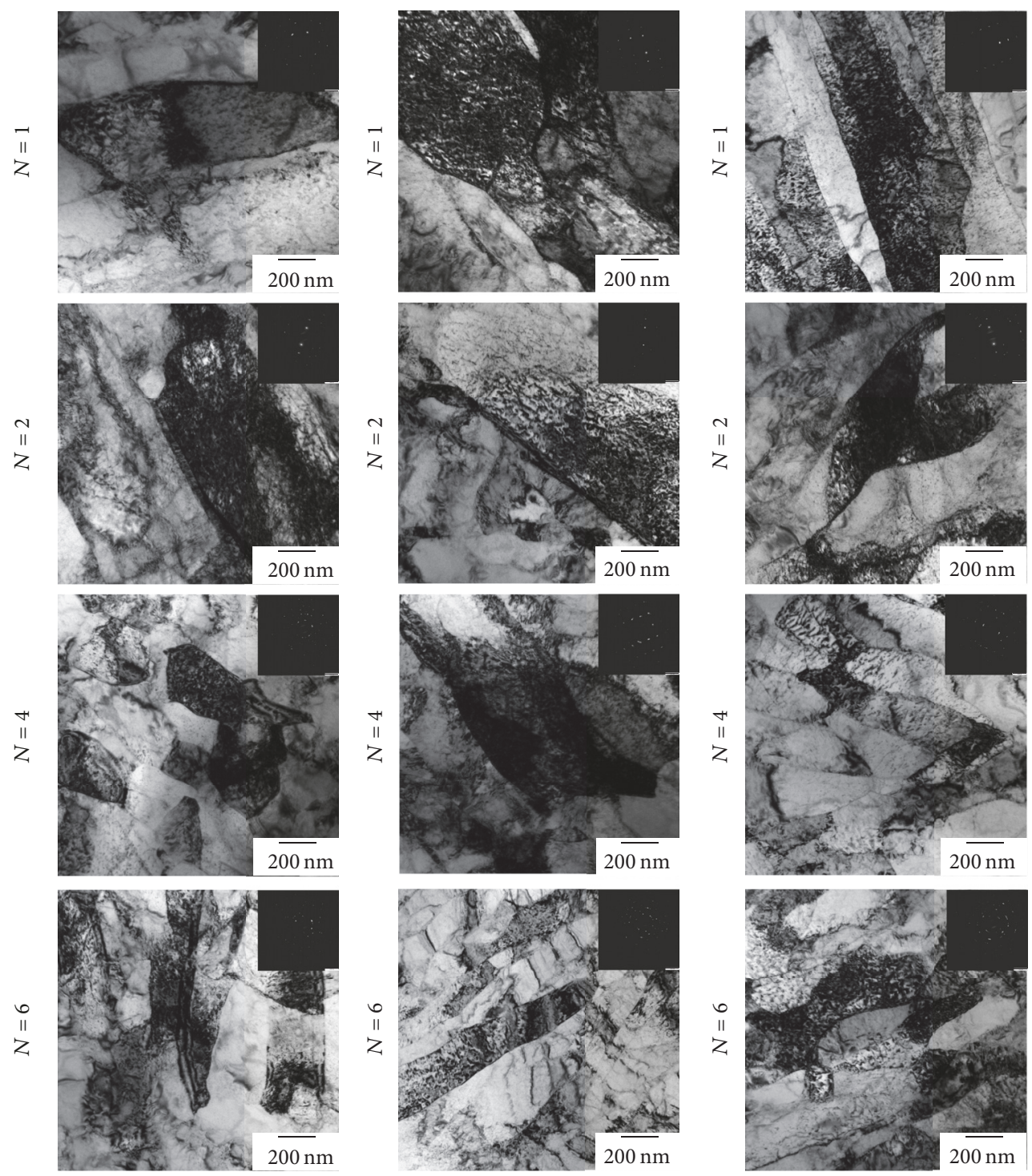

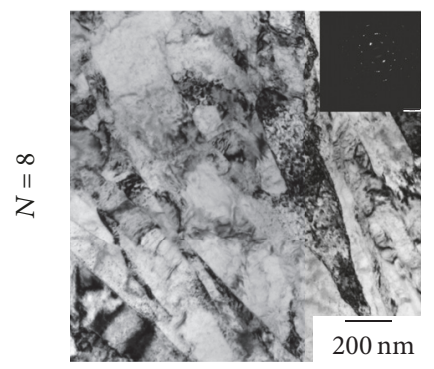

(a)

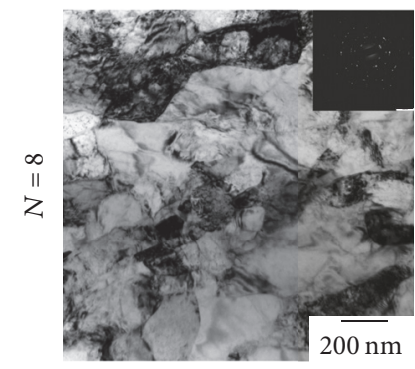

(b)

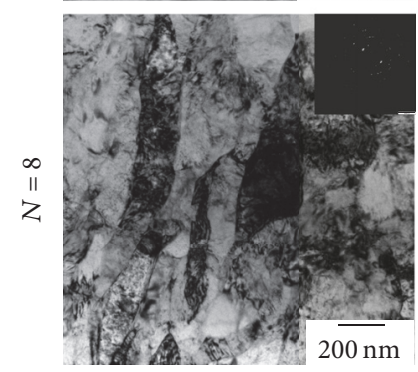

(c)

FIgURE 5: TEM images of Fe-Cr processed by ECAP with (a) $8 \% \mathrm{Cr}$, (b) $10 \% \mathrm{Cr}$, and (c) $12 \% \mathrm{Cr}$.

become more refined and equiaxed, in addition to being more uniform in size, after six and eight passes. This is the result of repeated strain along different routes, which activates multiple slip systems and causes shear deformation bands to intersection [7]. From the EBSD maps, the average grain size $d^{-0.5}$ was determined to be 199,180 , and $176 \mathrm{~nm}$ for alloys with 8,10 , and $12 \% \mathrm{Cr}$, respectively, following eight ECAP passes. With increasing number of ECAP passes, the grain size decreased for all samples, regardless of $\mathrm{Cr}$ content, as seen in Figure 3. Figure 4 shows the dependence of the Vickers microhardness on the number of ECAP passes. The microhardness increases rapidly with increasing number of 


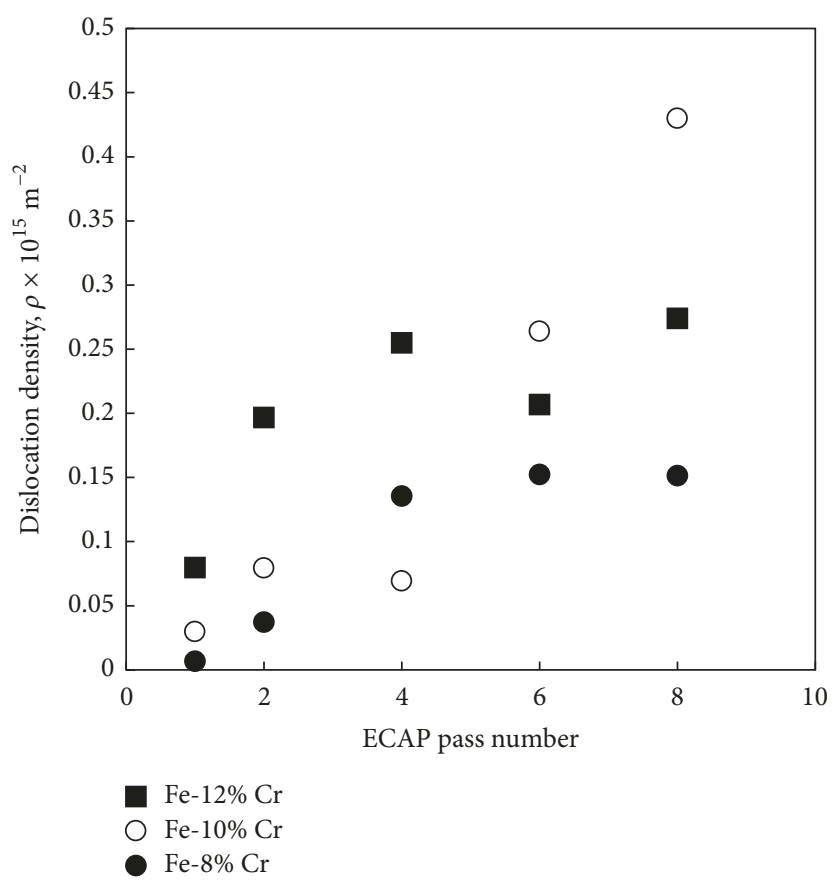

FIgUre 6: Dependence of dislocation density for Fe-Cr alloy on number of ECAP passes.

ECAP passes, due to the higher dislocation density and strengthening due to grain refinement $[13,14]$.

By increasing the number of ECAP passes or the equivalent strain, the dislocation density increases and a subgrain structure begins to form [15]. This subgrain structure, together with the large number of dislocations and nonequilibrium grain boundaries, leads to work hardening and an increase in the strength of the material due to the difficulty of dislocation movement inside the grains; this has been verified by TEM and XRD measurements [13]. Figure 5 shows TEM images of specimens subjected to one, two, four, six, and eight ECAP passes. After one pass, the grains are elongated and dislocations are present at the grain boundaries. For higher numbers of passes, the nonequilibrium grain boundaries are easy to observe. Grain fragmentation also can be seen in the initial of UFG structure formation. Following a single ECAP pass, the specimen is finely subdivided into grains and dislocations both at grain boundaries and within the grains. The microstructure following the initial deformation process consists of low-angle grain boundaries, as is evidenced by the blurred appearance of the grain boundaries in the TEM images [15]. After two ECAP passes, the microstructure became finer and consisted of elongated grains with more planar boundaries. The dislocation density significantly increased after two passes. After four passes, the microstructure consisted of more equiaxed UFGs with sharper boundaries. The sharpest grain boundaries were observed following eight passes. The insets in Figure 5 show selected area diffraction patterns corresponding to the TEM images. Up to six ECAP passes, the patterns are spot-like, indicating the presence of LAGBs and a high dislocation density inside grains or at grain boundaries which can be indicated from XRD peak broadening. However, after eight passes, the pattern becomes ring-like, indicating a UFG structure with a large fraction of HAGBs. This is consistent with the TEM observation results, which indicated that a higher fraction of HAGBs was present following eight ECAP passes, whereas a smaller number of passes produced mainly dislocations.

The dislocation density was calculated using a Williamson-Hall plot based on the full width at half maximum of XRD diffraction peaks. Broadening of the peaks occurs due to the presence of dislocations and nonequilibrium grain boundaries containing extrinsic defects and subjected to elastic stress [7]. The calculations were performed using the (110), (200), (211), (220), and (310) diffraction peaks. Figure 6 shows the dependence of the dislocation density on the number of ECAP passes. As a result of grain refinement, the dislocation density increases with increasing number of ECAP passes, and after eight passes it is about three times higher than after one pass. This is in agreement with our previous findings for Fe alloy with $20 \%$ Cr [15].

The effect of the deformation structure on the corrosion resistance was investigated in a $1000 \mathrm{~mol} \cdot \mathrm{m}^{-3} \mathrm{NaCl}$ solution at room temperature by potentiodynamic polarization. Anodic polarization curves for the as-annealed specimen and specimens following one, two four, six, and eight ECAP passes are shown in Figure 7. The results are divided into two groups. In Group A, no passivation layer was present on the surface (intergranular corrosion), whereas in Group $\mathrm{B}$ a passivation layer was present (pitting corrosion). $\mathrm{Fe}-\mathrm{Cr}$ 

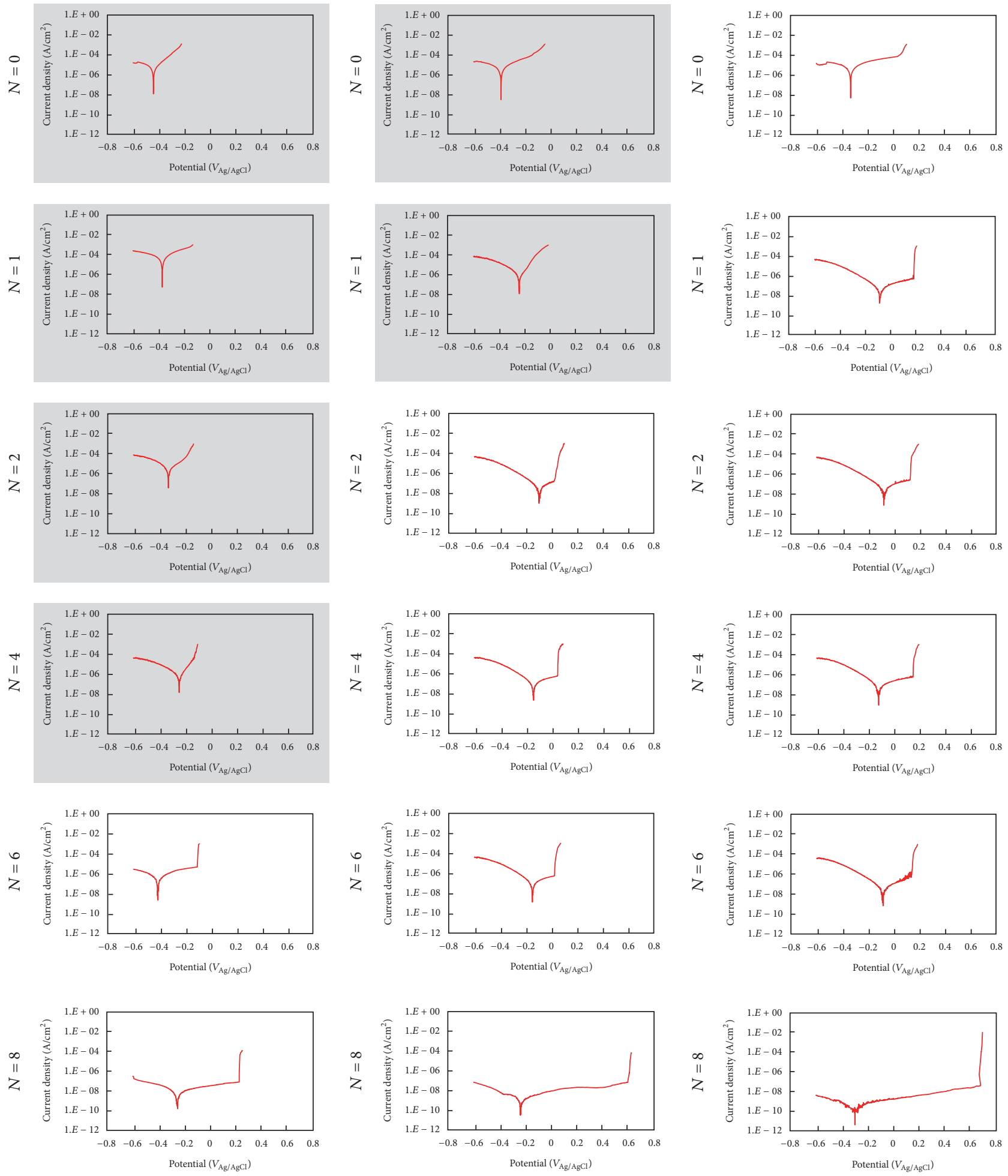

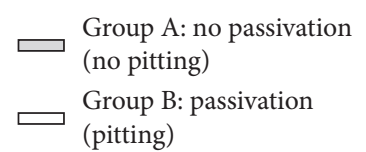

(a)

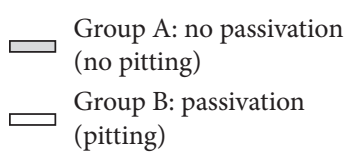

(b)

$$
\begin{aligned}
& \text { Group B: passivation } \\
& \text { (pitting) }
\end{aligned}
$$

(c)

Figure 7: Anodic polarization curves of Fe-Cr alloy processed by ECAP with (a) $8 \% \mathrm{Cr}$, (b) $10 \% \mathrm{Cr}$, and (c) $12 \% \mathrm{Cr}$ in $1000 \mathrm{~mol} \cdot \mathrm{m}^{-3} \mathrm{NaCl}$ solution. 


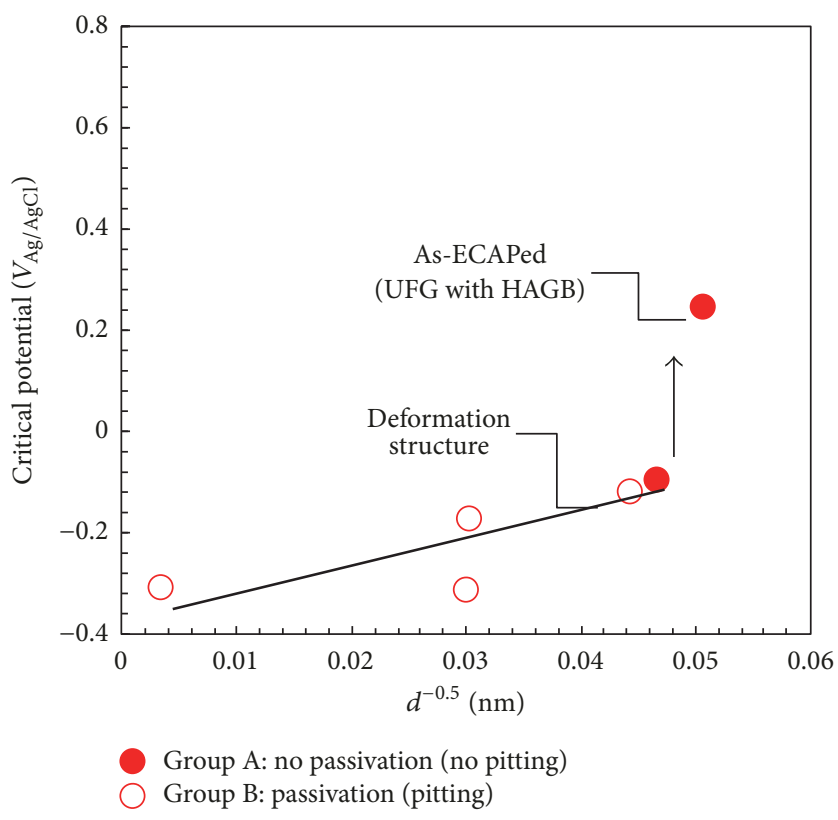

(a)

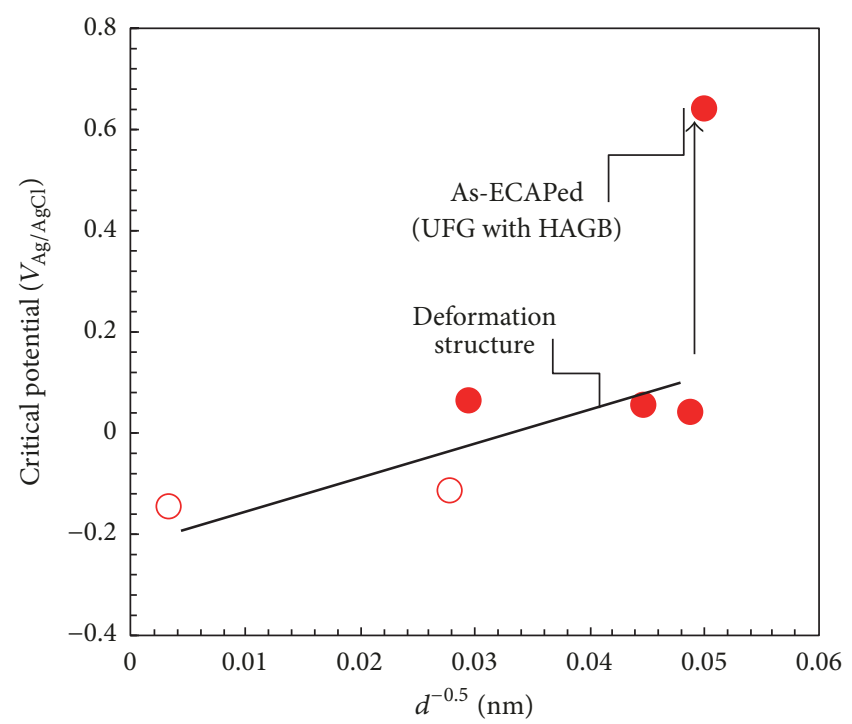

Group A: no passivation (no pitting)

Group B: passivation (pitting)

(b)

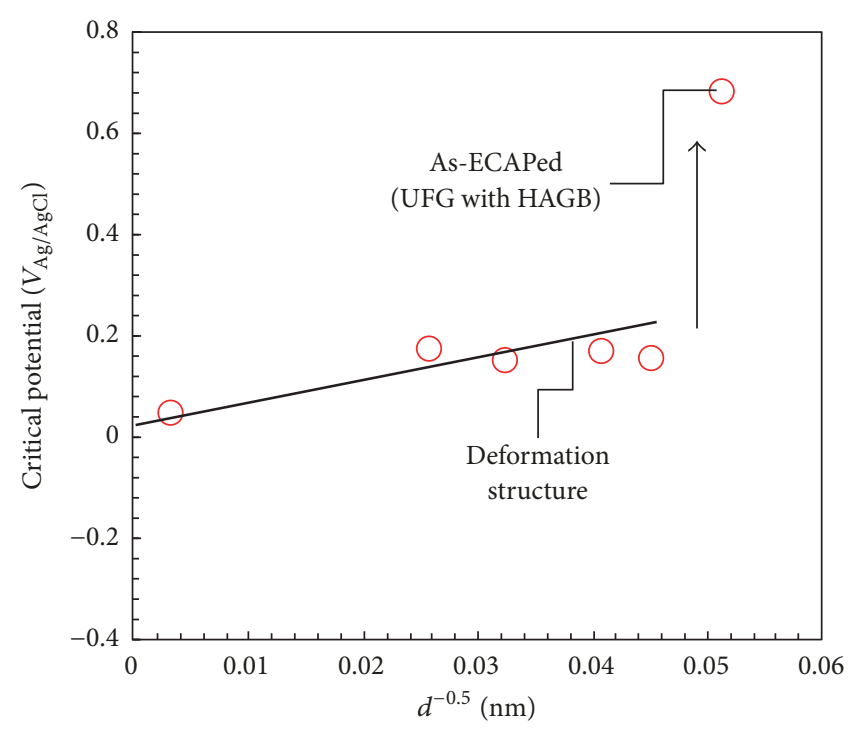

Group B: passivation (pitting)

(c)

Figure 8: Potential at $0.1 \mathrm{~mA} / \mathrm{cm}^{2}$ and grain size of Fe-Cr alloy processed by ECAP with (a) $8 \% \mathrm{Cr}$, (b) $10 \% \mathrm{Cr}$, and (c) $12 \%$ Cr.

alloy with 8 and $10 \% \mathrm{Cr}$ showed no passivation until four ECAP passes and one pass, respectively. However, the $\mathrm{Fe}-\mathrm{Cr}$ alloy with $12 \%$ Cr showed passivation from the beginning of the grain refinement process. This means that, in the case of $8 \% \mathrm{Cr}$, far more grain refinement and a higher dislocation density are required in order to achieve the same level of passivation as that for 10 and $12 \% \mathrm{Cr}$. The critical potential, which is defined as the potential required for the anodic current density to reach $0.1 \mathrm{~mA} \cdot \mathrm{cm}^{-2}$, increased with the number of passes and became positive, so that the passivation range became longer or nobler.

The critical potential is plotted against the average grain size $d^{-0.5}$ in Figure 8 . It is clear that all the samples produced by ECAP have a nobler potential than the as-annealed sample. The polarization results imply that corrosion resistance is enhanced by ECAP regardless of the Cr content. The most 


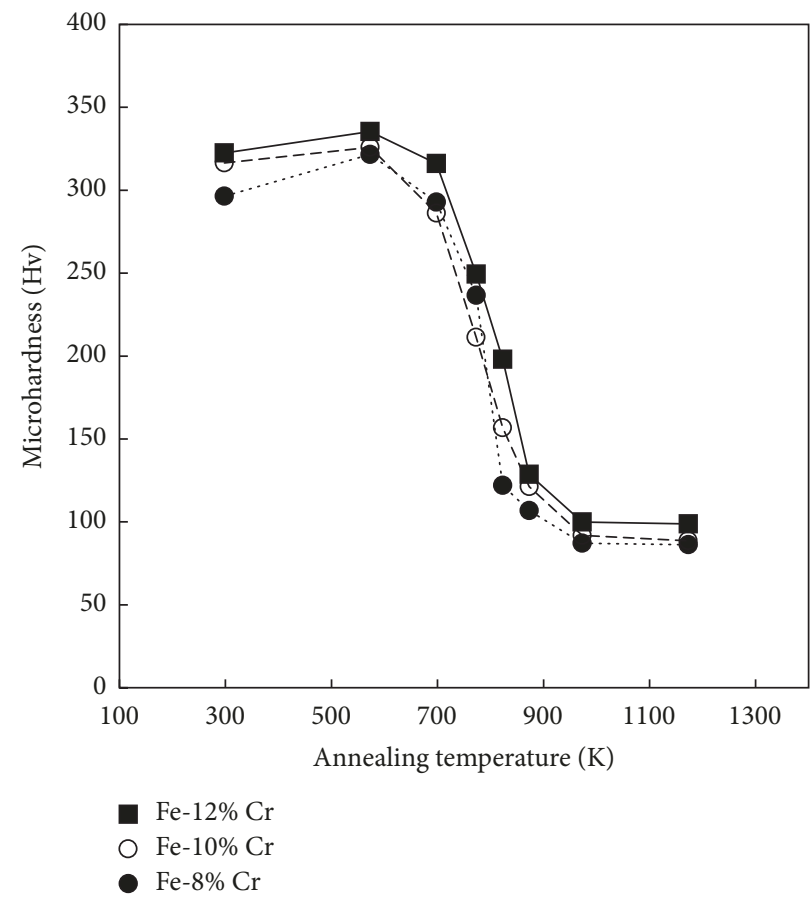

FIGURE 9: Relationship between microhardness and post-ECAP annealing temperature.

extended passivation range, representing higher corrosion resistance, is found following eight ECAP passes. It is interesting to note that even though the Cr content is less than that required for stainless steel, UFG material with 8 and $10 \%$ Cr showed improved corrosion resistance due to the stability of the passivation layer in the $1000 \mathrm{~mol} \cdot \mathrm{m}^{-3} \mathrm{NaCl}$ solution. Following eight passes, the specimen exhibited a high fraction of HAGBs instead of mainly dislocations, as can be seen in Figure 5. This means that a high HAGB fraction can increase the critical potential and the stability of the passivation layer, thus reducing the critical $\mathrm{Cr}$ content for stainless steel.

To investigate the effect of the state of equilibrium of the grain boundaries on the corrosion resistance, heat treatment was applied to the UFG material. Figure 9 shows the change in the microhardness of UFG samples by eight passes of ECAP, subjected to heat treatments at temperatures of $473-1173 \mathrm{~K}$ for $1 \mathrm{~h}$. At $698 \mathrm{~K}$, the initial hardness remains; this corresponds to the recovery stage in which dislocations are annihilated and grain boundaries change to an equilibrium state [16]. By $973 \mathrm{~K}$, the hardness has drastically decreased to around $100 \mathrm{HV}$, indicating the completion of the recrystallization stage, accompanied by grain growth. Figure 10 shows EBSD misorientation maps for UFG specimens subjected to heat treatments at $573,698,773,873,973$, and $1173 \mathrm{~K}$. The recovery stage can be seen until $698 \mathrm{~K}$, and there is no significant change in grain size. At $698 \mathrm{~K}$, several new grains are seen to have nucleated along the shear bands, and this is related to the recrystallization stage. At $873 \mathrm{~K}$, recrystallized grains grow by annihilating deformed grains. This is the grain growth stage in which the hardness has not changed and the microstructure showed equiaxed grain appearance. The effect of the annealing temperature on the grain size is shown in Figure 11. In addition, Figure 12 plots anodic polarization curves for USG specimens following heat treatments at different temperatures. These results were also divided into two groups, as described earlier. Regardless of the $\mathrm{Cr}$ content, the specimens exhibited stable passivation until the recovery stage, but those with 10 and $12 \% \mathrm{Cr}$ maintained their passivation to a temperature of $50 \mathrm{~K}$ higher than the $8 \% \mathrm{Cr}$ specimen. The occurrence of pitting is indicated by an abrupt increase in the anodic current at a nobler potential than that for a sample with passivation [17-19]. In Figure 12, it becomes more difficult to identify the pitting potential as the annealing temperature increases. The high anodic current in UFG material with a high density of nonequilibrium grain boundaries may be associated with the stability of the passivation layer. The critical potential at $0.1 \mathrm{~mA} / \mathrm{cm}^{2}$ is plotted as a function of grain size in Figure 13. The UFG material shows a more negative OCP than the as-annealed specimen due to higher fraction of nonequilibrium grain boundaries. Here also, the passivation range increases with increasing number of ECAP passes. The surface after anodic polarization was observed by laser microscopy and could be divided into two groups based on the anodic polarization results. The first group (Group A) exhibited no pitting (intergranular corrosion), which was related to the absence of a passivation layer. This group included, for example, the coarse-grained specimens with 8 and 10\% Cr seen in Figures 14(a) and 14(b). The second group (Group B) included all UFG specimens and 

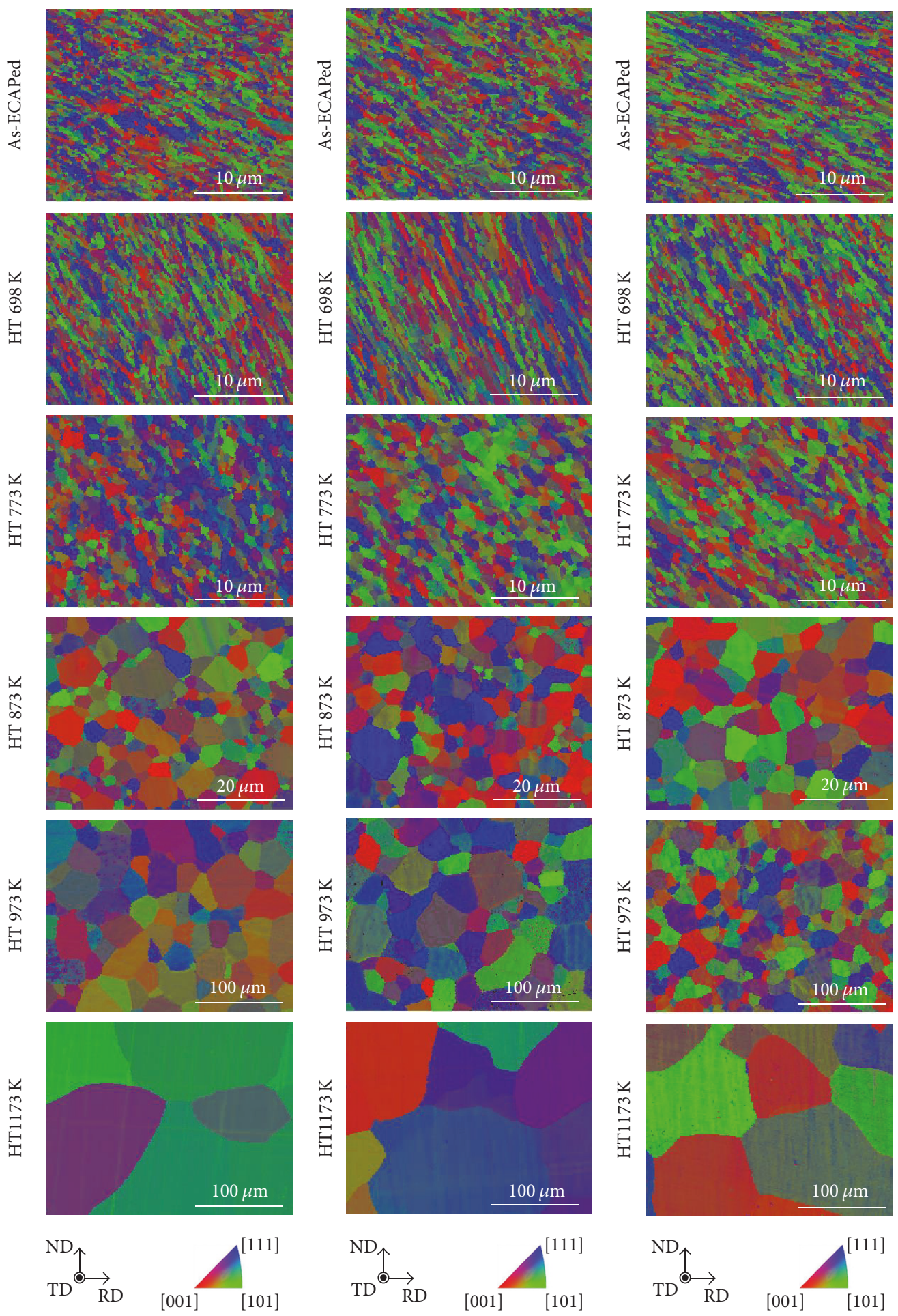

(a)

(b)

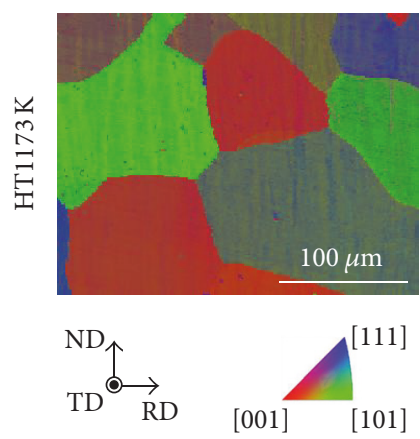

(c)

FIGURE 10: Color orientation maps obtained by EBSD after post-ECAP annealing with (a) $8 \%$ Cr, (b) $10 \%$ Cr, and (c) $12 \%$ Cr.

the as-annealed specimen with $12 \% \mathrm{Cr}$, as seen in Figures 14(c)-14(f). The anodic polarization tests indicated that the specimen produced using eight ECAP passes with a high density of nonequilibrium grain boundaries had a more stable passivation layer than specimens produced using a smaller number of ECAP passes or the as-annealed specimen.

The present result shows that the superiority of asECAPed materials of the Fe-Cr alloy to recovered ones can be 


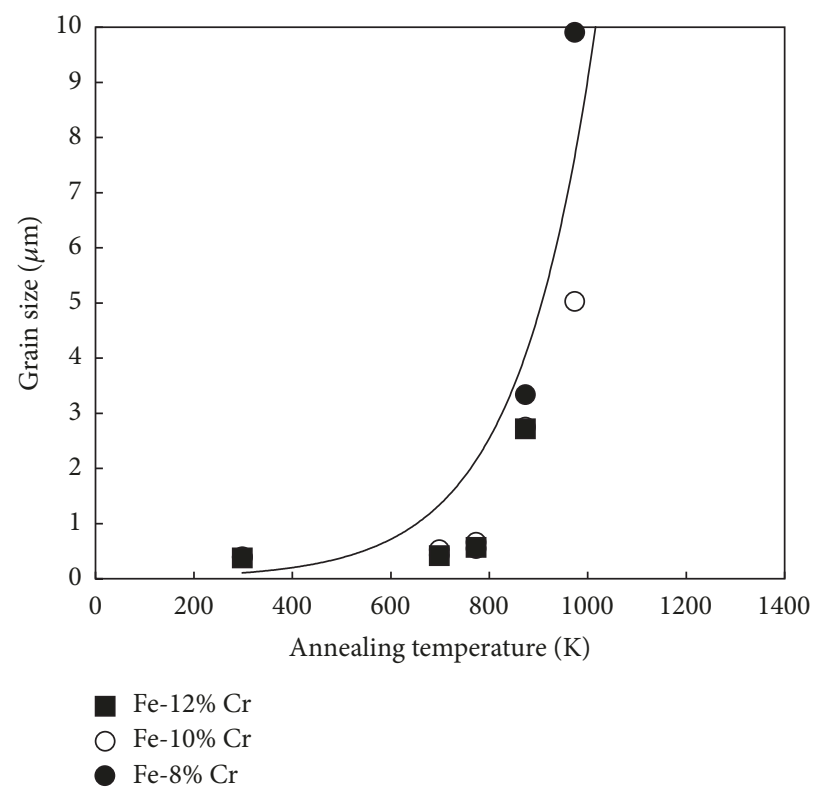

FIGURE 11: Effect of post-ECAP annealing temperature on grain size.

achieved even with $8-10 \% \mathrm{Cr}$ as observed in $20 \% \mathrm{Cr}$ [7]. The deformation structure, nonequilibrium grain boundaries, and chemical composition of the Fe-Cr alloy may have a high impact on the corrosion resistance. It is generally considered that the $\mathrm{Cr}$ content in particular plays a leading role in corrosion resistance [20-25]. Improved corrosion resistance can be achieved when the $\mathrm{Cr}$ content is above the critical value for stainless steel [26]. Asami et al. showed that the $\mathrm{Cr}$ content, expressed as $\mathrm{Cr} /(\mathrm{Fe}+\mathrm{Cr})$, of the passivation layer increased by six times when the $\mathrm{Cr}$ content in the alloy was $13-15 \%$ [26]. This implies that the corrosion resistance of Fe$\mathrm{Cr}$ alloy depends on the $\mathrm{Cr}$ content in the alloy. The corrosion resistance is related to the formation of a passivation layer on the surface of the metal. The addition of $\mathrm{Cr}$ to iron leads to an improvement in corrosion resistance by replacing the iron oxide passivation layer with $\mathrm{Cr}$ oxide [20]. It is therefore essential to determine the critical $\mathrm{Cr}$ content required to improve the corrosion resistance and the pitting resistance $[27,28]$. Corrosion of Fe-Cr alloy depends on the properties of the passivation layer, which are mainly determined by the $\mathrm{Cr}$ content of the alloy. The general theory of corrosion resistance is based on the selective dissolution of iron and oxidation of $\mathrm{Cr}$ manages the formation of the passive film $[29,30]$. Previous research suggested that more than $50 \%$ $\mathrm{Cr}$ is required in the passivation layer in order to make it stable [26]. It was also reported that, by increasing the $\mathrm{Cr}$ content in the bulk, the passivation layer showed a significant improvement $[31,32]$. In a binary system such as $\mathrm{Fe}-\mathrm{Cr}$ alloy, corrosion initiation depends on the formation of iron clusters [32]. The size of these clusters influences local dissolution and the occurrence of pitting. However, the iron clusters are also affected by the Cr content in the alloy, which is referred to as the critical value [20-25]. It can be expected that the deformation structure and the presence of nonequilibrium grain boundaries can influence the critical $\mathrm{Cr}$ content in stainless steel. The extended stability of the passivation layer in Fe$\mathrm{Cr}$ alloys with 8 and 10\% Cr can be explained by enhanced diffusion of $\mathrm{Cr}$ due to the high density of nonequilibrium grain boundaries $[24,33,34]$ and also by the passivation layer formed by selective iron dissolution at the surface $[5,6]$. The rapid diffusion of $\mathrm{Cr}$ was supplied by the $\mathrm{Cr}$ stored in the dislocation, grains, and nonequilibrium grain boundaries [35, 36]. Based on the GD-OES Cr profile shown in Figure 15, the passivation layer on UFG material is richer than that in $\mathrm{Cr}$ on $\mathrm{CG}$ material. This is an indication of enhanced $\mathrm{Cr}$ diffusion in the UFG structure, leading to a composition change in the passivation layer and higher corrosion resistance.

\section{Conclusion}

The effect of $\mathrm{Cr}$ content and post-ECAP annealing temperature on the corrosion behavior of UFG Fe-Cr alloy with 8, 10, and $12 \%$ Cr was investigated, focusing on the stability of the passivation layer. The following conclusions were obtained:

(1) Passivation characteristics appeared in the anodic polarization results for all UFG alloys after ECAP, and the critical potential for UFG material was higher than that for CG material before ECAP. However, the critical potential decreased was by post-ECAP annealing.

(2) Destabilization of the passivation and a drastic drop in the pitting potential were observed following moderate-temperature annealing, as the grain boundaries changed from a nonequilibrium to an equilibrium state with no significant grain growth.

(3) Nonequilibrium grain boundaries may facilitate the formation of a passivation layer in $\mathrm{Fe}-\mathrm{Cr}$ alloys with 

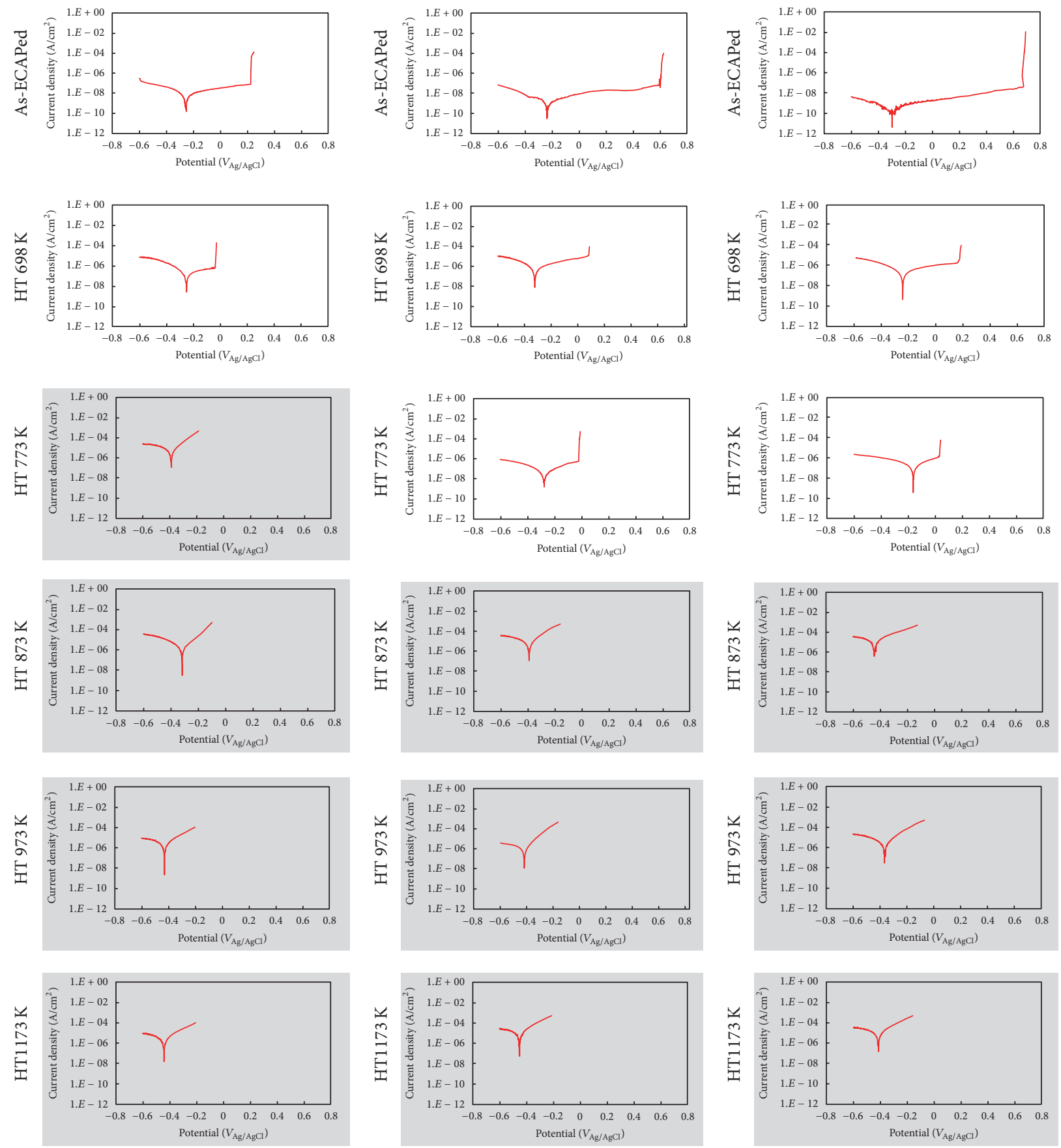

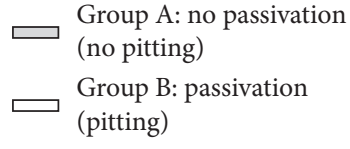

(a)

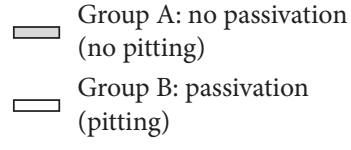

(b)

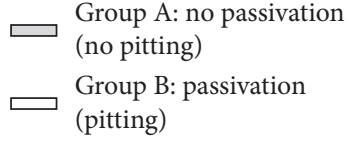

(c)

FIGURE 12: Anodic polarization curves for post-ECAP annealed samples in $1000 \mathrm{~mol} \cdot \mathrm{m}^{-3} \mathrm{NaCl}$ solution with (a) $8 \% \mathrm{Cr}$, (b) $10 \% \mathrm{Cr}$, and (c) $12 \% \mathrm{Cr}$. 


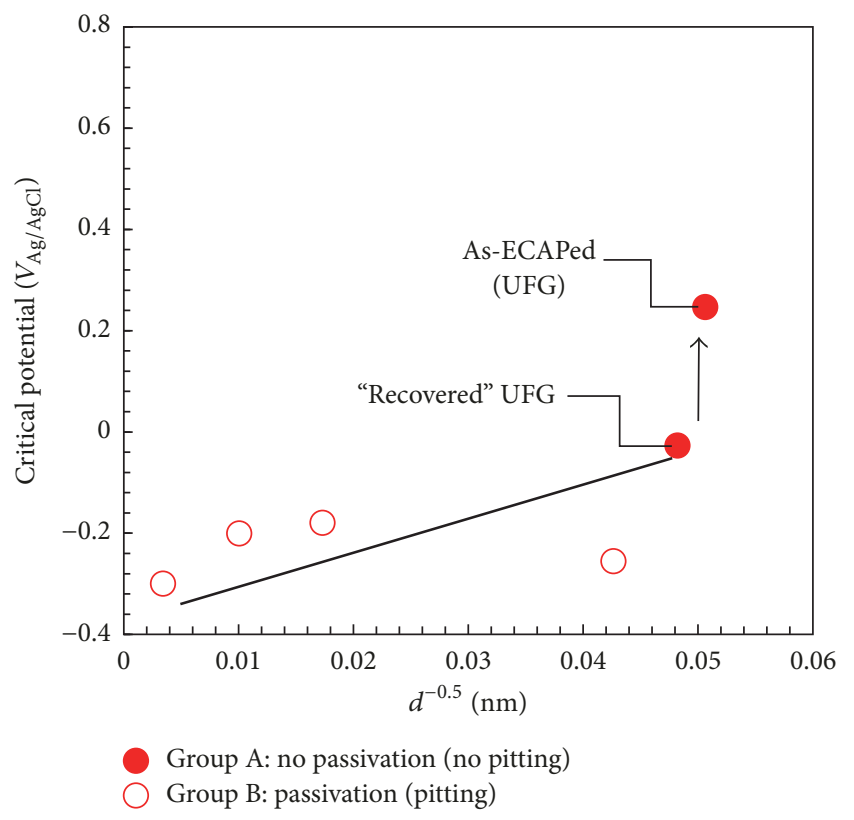

(a)

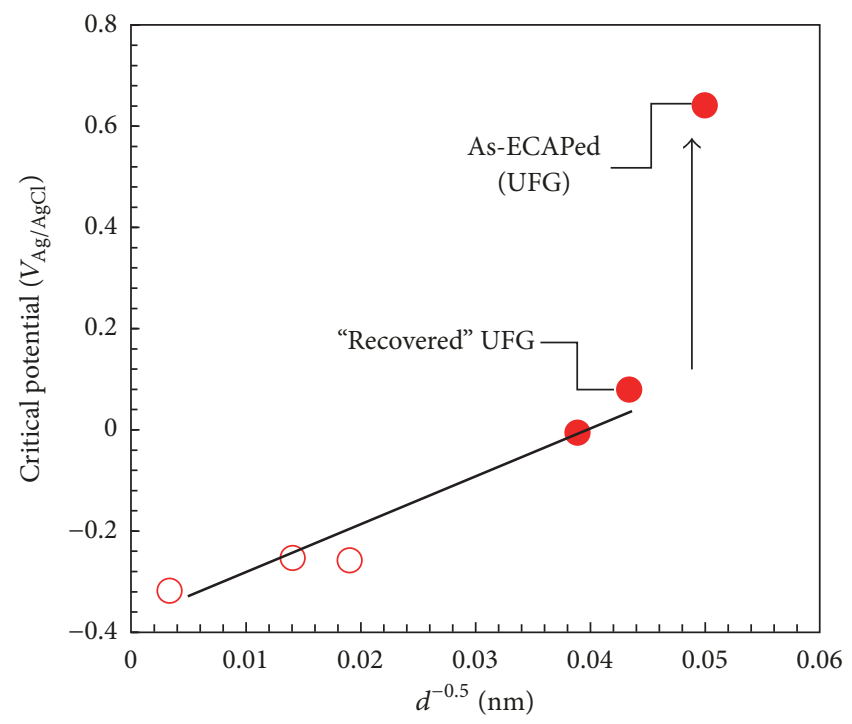

Group A: no passivation (no pitting)

Group B: passivation (pitting)

(b)

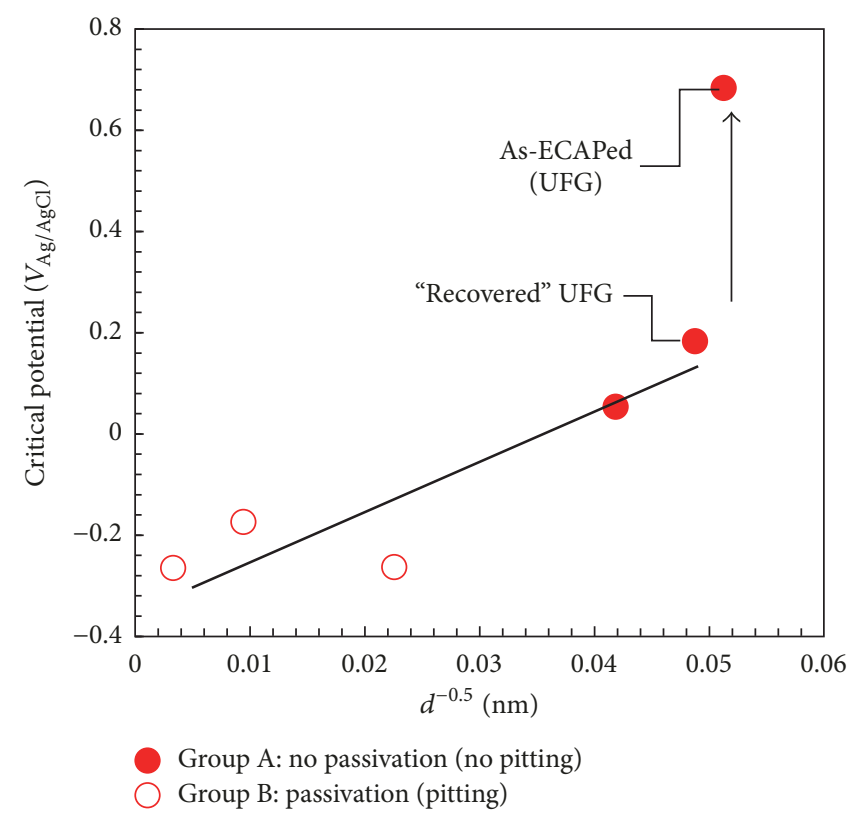

(c)

Figure 13: Potential at $0.1 \mathrm{~mA} / \mathrm{cm}^{2}$ and grain size of post-ECAP annealed sample.

a Cr content of less than $10 \%$, which is generally considered to be the minimum value.

(4) A UFG specimen produced by eight ECAP passes exhibited a deformation structure with a higher fraction of HAGBs; other specimens mainly contained dislocations. This is consistent with the higher critical potential for the former specimen. This means that a high HAGB fraction can improve the critical potential and the stability of the passivation layer and also reduce the $\mathrm{Cr}$ limit required for stainless steel.

\section{Conflicts of Interest}

The authors declare that there are no conflicts of interest regarding the publication of this paper. 


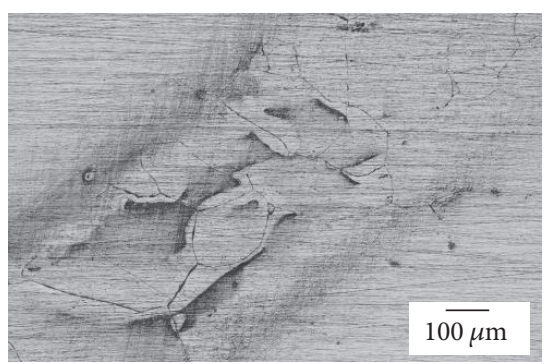

(a)

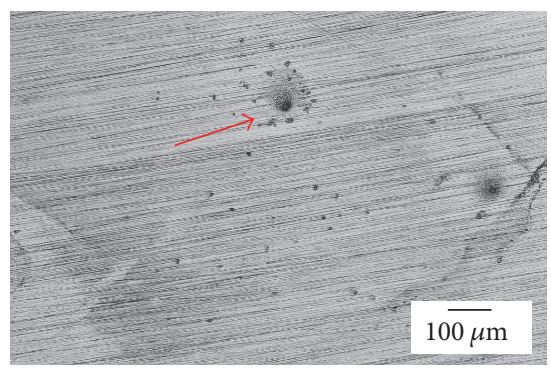

$\longrightarrow$ Pitting

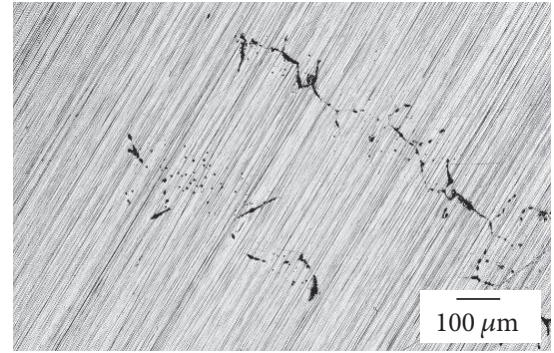

(b)

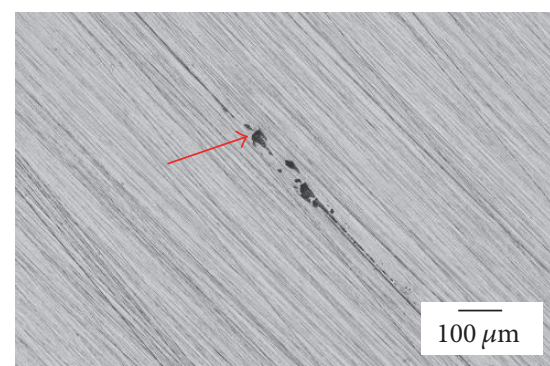

$\longrightarrow$ Pitting

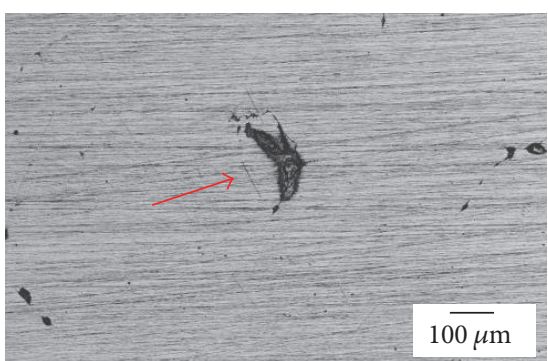

$\longrightarrow$ Pitting

(c)

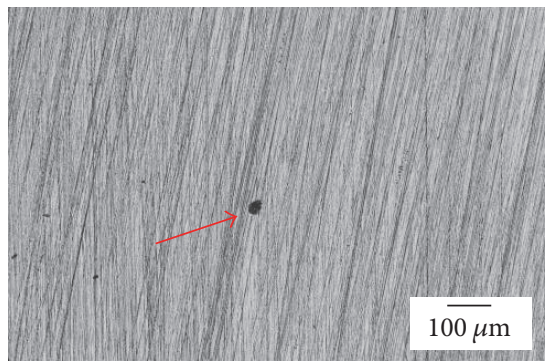

$\longrightarrow$ Pitting

(d)

(e)

(f)

FIGURE 14: Surface appearance after anodic polarization test on as-ECAP processed sample with (a) $8 \% \mathrm{Cr}$, (b) $10 \% \mathrm{Cr}$, and (c) $12 \% \mathrm{Cr}$ and grain growth stage (CG structure) with (d) $8 \% \mathrm{Cr}$, (e) $10 \% \mathrm{Cr}$, and (f) $12 \% \mathrm{Cr}$ by laser microscopy.

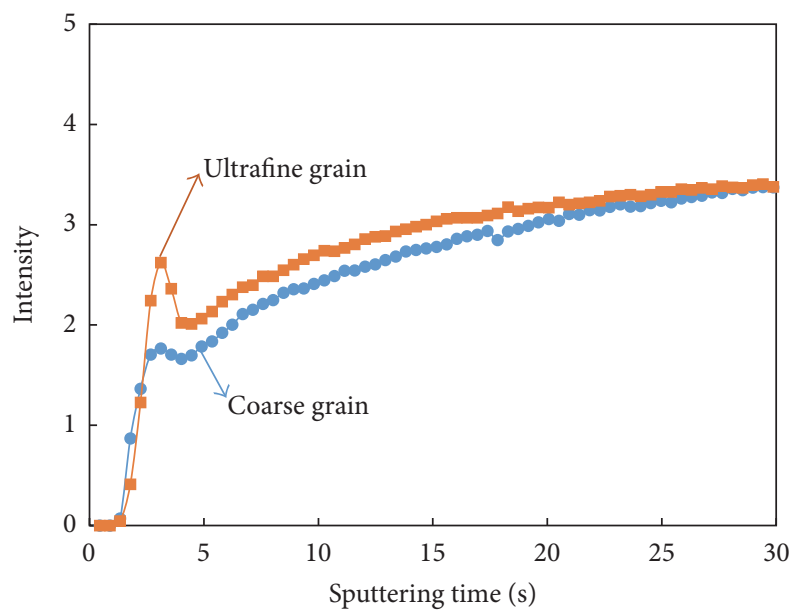

FIgure 15: Cr profile obtained by GD-OES for Fe-10\% Cr.

\section{References}

[1] R. Z. Valiev, Y. Estrin, Z. Horita, T. G. Langdon, M. J. Zechetbauer, and Y. T. Zhu, "Producing bulk ultrafine-grained materials by severe plastic deformation," JOM Journal of the Minerals, Metals and Materials Society, vol. 58, no. 4, pp. 33-39, 2006.

[2] R. Z. Valiev and T. G. Langdon, "Principles of equal-channel angular pressing as a processing tool for grain refinement," Progress in Materials Science, vol. 51, no. 7, pp. 881-981, 2006.
[3] M. W. Grabski, "Mechanical properties of internal interfaces," Le Journal de Physique Colloques, vol. 46, no. C4, pp. C4-567C4-579, 1985.

[4] R. Z. Valiev, V. Y. Gertsman, and O. A. Kaibyshev, "Grain boundary structure and properties under external influences," Physica Status Solidi (a) - Applications and Materials Science, vol. 97, no. 1, pp. 11-56, 1986.

[5] K. Sieradzki and R. C. Newman, "A percolation model for passivation in stainless steels," Journal of The Electrochemical Society, vol. 133, no. 9, pp. 1979-1980, 1986.

[6] S. Qian, R. C. Newman, R. A. Cottis, and K. Sieradzki, "Validation of a percolation model for passivation of $\mathrm{Fe}-\mathrm{Cr}$ alloys: Two-dimensional computer simulations," Journal of The Electrochemical Society, vol. 137, no. 2, pp. 435-439, 1990.

[7] M. Rifai, H. Miyamoto, and H. Fujiwara, "Effects of strain energy and grain size on corrosion resistance of ultrafine grained $\mathrm{Fe}-20 \% \mathrm{Cr}$ steels with extremely low $\mathrm{C}$ and $\mathrm{N}$ fabricated by ECAP," International Journal of Corrosion, vol. 2015, Article ID 386865, 9 pages, 2015.

[8] Z. J. Zheng, Y. Gao, Y. Gui, and M. Zhu, "Corrosion behaviour of nanocrystalline 304 stainless steel prepared by equal channel angular pressing," Corrosion Science, vol. 54, no. 1, pp. 60-67, 2012.

[9] Y. Gui, Z. J. Zheng, and Y. Gao, "The bi-layer structure and the higher compactness of a passive film on nanocrystalline 304 stainless steel," Thin Solid Films, vol. 599, pp. 64-71, 2016.

[10] M. Pisarek, P. Kedzierzawski, T. Płociński, M. Janik-Czachor, and K. J. Kurzydłowski, "Characterization of the effects of hydrostatic extrusion on grain size, surface composition and 
the corrosion resistance of austenitic stainless steels," Materials Characterization, vol. 59, no. 9, pp. 1292-1300, 2008.

[11] M. Rifai, H. Miyamoto, and H. Fujiwara, "The Effect of ECAP Deformation Route on Microstructure, Mechanical and Electrochemical Properties of Low CN Fe-20\% Cr Alloy," Materials Sciences and Applications, vol. 5, no. 08, p. 568, 2014.

[12] S. S. Kumar, M. Vasanth, V. Singh, P. Ghosal, and T. Raghu, "An investigation of microstructural evolution in 304L austenitic stainless steel warm deformed by cyclic channel die compression," Journal of Alloys and Compounds, vol. 699, pp. 1036-1048, 2017.

[13] S. V. Muley, A. N. Vidvans, G. P. Chaudhari, and S. Udainiya, "An assessment of ultra fine grained 316L stainless steel for implant applications," Acta Biomaterialia, vol. 30, pp. 408-419, 2016.

[14] J. R. Weertman, "Hall-Petch strengthening in nanocrystalline metals," Materials Science and Engineering: A Structural Materials: Properties, Microstructure and Processing, vol. 166, no. 1-2, pp. 161-167, 1993.

[15] M. Rifai, H. Miyamoto, and H. Fujiwara, "Effect of ECAP deformation route on the degree of anisotropy of microstructure of extremely low CN Fe-20mass\% Cr alloy," Metals, vol. 4, no. 1, pp. 55-63, 2014.

[16] A. Belyakov, T. Sakai, H. Miura, R. Kaibyshev, and K. Tsuzaki, "Continuous recrystallization in austenitic stainless steel after large strain deformation," Acta Materialia, vol. 50, no. 6, pp. 1547-1557, 2002.

[17] H. P. Leckie and H. H. Uhlig, "Environmental factors affecting the critical potential for pitting in 18-8 stainless steel," Journal of The Electrochemical Society, vol. 113, no. 12, pp. 1262-1267, 1966.

[18] J. Horvath and H. H. Uhlig, "Critical potentials for pitting corrosion of $\mathrm{Ni}, \mathrm{Cr}-\mathrm{Ni}, \mathrm{Cr}-\mathrm{Fe}$, and related stainless steels," Journal of the Electrochemical Society, vol. 115, no. 8, pp. 791-795, 1968.

[19] G. S. Frankel, "Pitting corrosion of metals: a review of the critical factors," Journal of the Electrochemical Society, vol. 145, no. 6, pp. 2186-2198, 1998.

[20] R. K. Gupta and N. Birbilis, "The influence of nanocrystalline structure and processing route on corrosion of stainless steel: A review," Corrosion Science, vol. 92, pp. 1-15, 2015.

[21] M. Naka, K. Hashimoto, and T. Masumoto, "Effect of metalloidal elements on corrosion resistance of amorphous ironchromium alloys," Journal of Non-Crystalline Solids, vol. 28, no. 3, pp. 403-413, 1978.

[22] R. K. Gupta, R. K. S. Raman, C. C. Koch, and B. S. Murty, "Effect of nanocrystalline structure on the corrosion of a Fe20Cr alloy," International Journal of Electrochemical Science, vol. 8, no. 5, pp. 6791-6806, 2013.

[23] R. S. Raman, R. K. Gupta, and C. C. Koch, "Resistance of nanocrystalline vis-à-vis microcrystalline $\mathrm{Fe}-\mathrm{Cr}$ alloys to environmental degradation and challenges to their synthesis," Philosophical Magazine, vol. 90, no. 23, pp. 3233-3260, 2010.

[24] R. K. Gupta, R. K. Singh Raman, and C. C. Koch, "Electrochemical characteristics of nano and microcrystalline $\mathrm{Fe}-\mathrm{Cr}$ alloys," Journal of Materials Science, vol. 47, no. 16, pp. 6118-6124, 2012.

[25] R. K. Gupta, R. K. Singh Raman, and C. C. Koch, "Fabrication and oxidation resistance of nanocrystalline Fe10Cr alloy," Journal of Materials Science, vol. 45, no. 17, pp. 4884-4888, 2010.

[26] K. Asami, K. Hashimoto, and S. Shimodaira, "An XPS study of the passivity of a series of iron-chromium alloys in sulphuric acid," Corrosion Science, vol. 18, no. 2, pp. 151-160, 1978.
[27] J. S. Noh, N. J. Laycock, W. Gao, and D. B. Wells, "Effects of nitric acid passivation on the pitting resistance of 316 stainless steel," Corrosion Science, vol. 42, no. 12, pp. 2069-2084, 2000.

[28] C. O. Olsson and D. Landolt, "Passive films on stainless steels-chemistry, structure and growth," Electrochimica Acta, vol. 48, no. 9, pp. 1093-1104, 2003.

[29] A. R. Brooks, C. R. Clayton, K. Doss, and Y. C. Lu, "On the role of $\mathrm{Cr}$ in the passivity of stainless steel," Journal of The Electrochemical Society, vol. 133, no. 12, pp. 2459-2464, 1986.

[30] I. O. Wallinder, J. Lu, S. Bertling, and C. Leygraf, "Release rates of chromium and nickel from 304 and 316 stainless steel during urban atmospheric exposure-A combined field and laboratory study," Corrosion Science, vol. 44, no. 10, pp. 2303-2319, 2002.

[31] T. P. Hoar, "The production and breakdown of the passivity of metals," Corrosion Science, vol. 7, no. 6, pp. 341-355, 1967.

[32] D. E. Williams, R. C. Newman, Q. Song, and R. G. Kelly, "Passivity breakdown and pitting corrosion of binary alloys," Nature, vol. 350, no. 6315, pp. 216-219, 1991.

[33] R. A. Andrievski, "Review stability of nanostructured materials," Journal of Materials Science, vol. 38, no. 7, pp. 1367-1375, 2003.

[34] C. C. Koch, "Structural nanocrystalline materials: an overview," Journal of Materials Science, vol. 42, no. 5, pp. 1403-1414, 2007.

[35] Y. R. Kolobov, G. P. Grabovetskaya, M. B. Ivanov, A. P. Zhilyaev, and R. Z. Valiev, "Grain boundary diffusion characteristics of nanostructured nickel," Scripta Materialia, vol. 44, no. 6, pp. 873-878, 2001.

[36] R. Würschum, S. Herth, and U. Brossmann, "Diffusion in nanocrystalline metals and alloys-a status report," Advanced Engineering Materials, vol. 5, no. 5, pp. 365-372, 2003. 


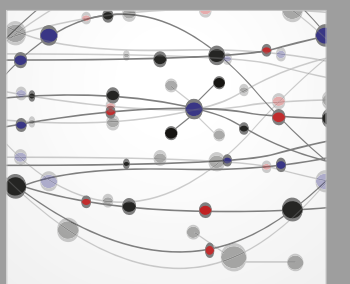

The Scientific World Journal
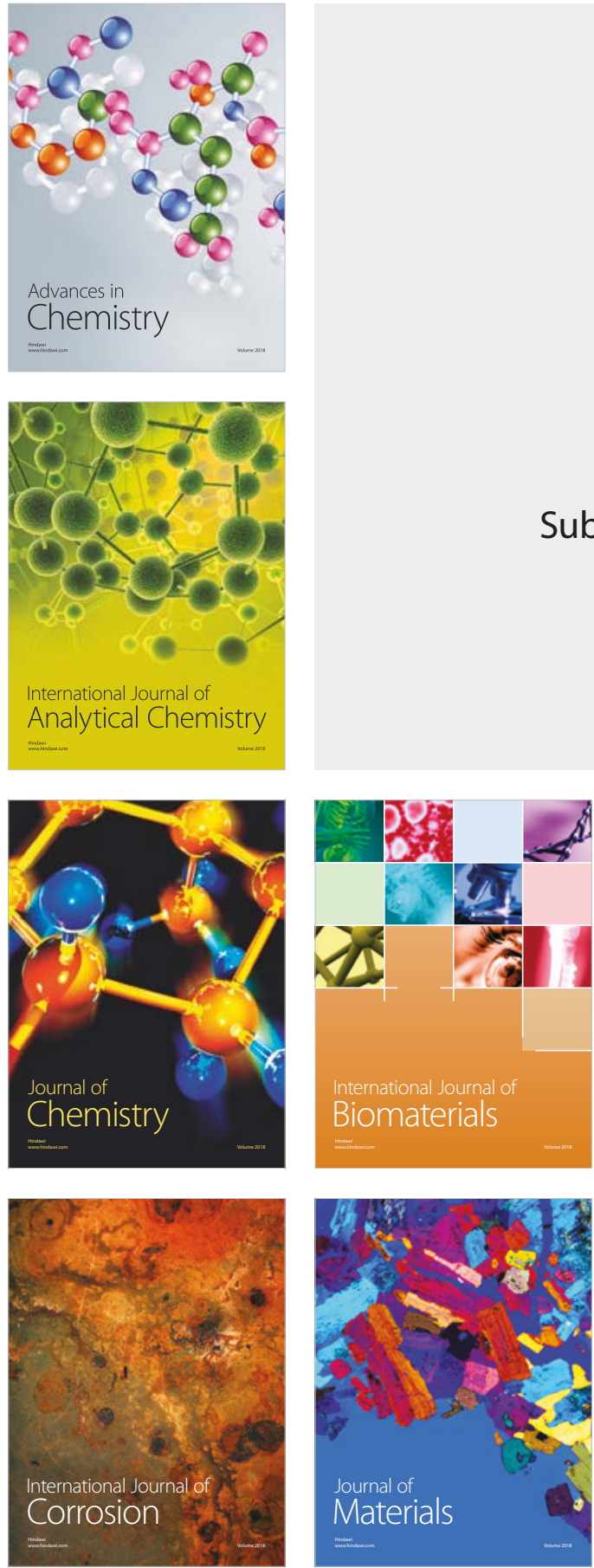

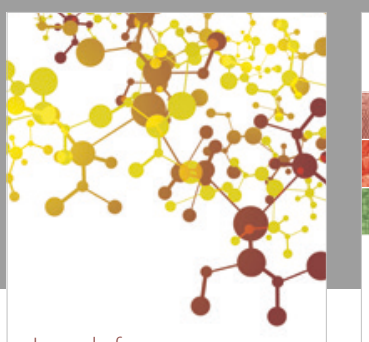

Journal of

Applied Chemistry
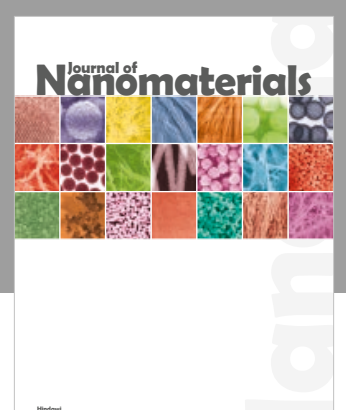

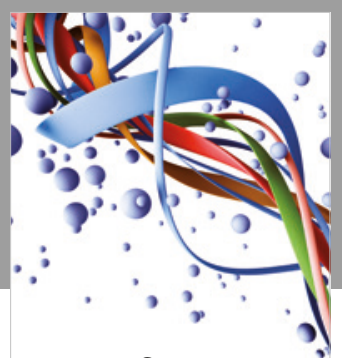

Scientifica

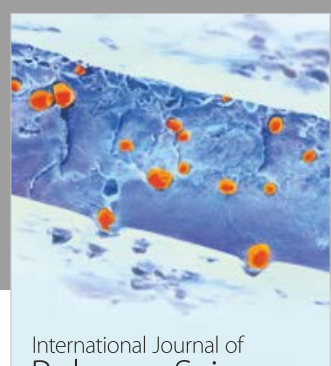

Polymer Science

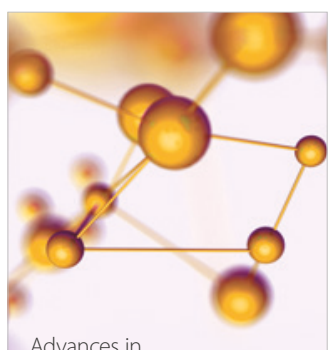

Physical Chemistry
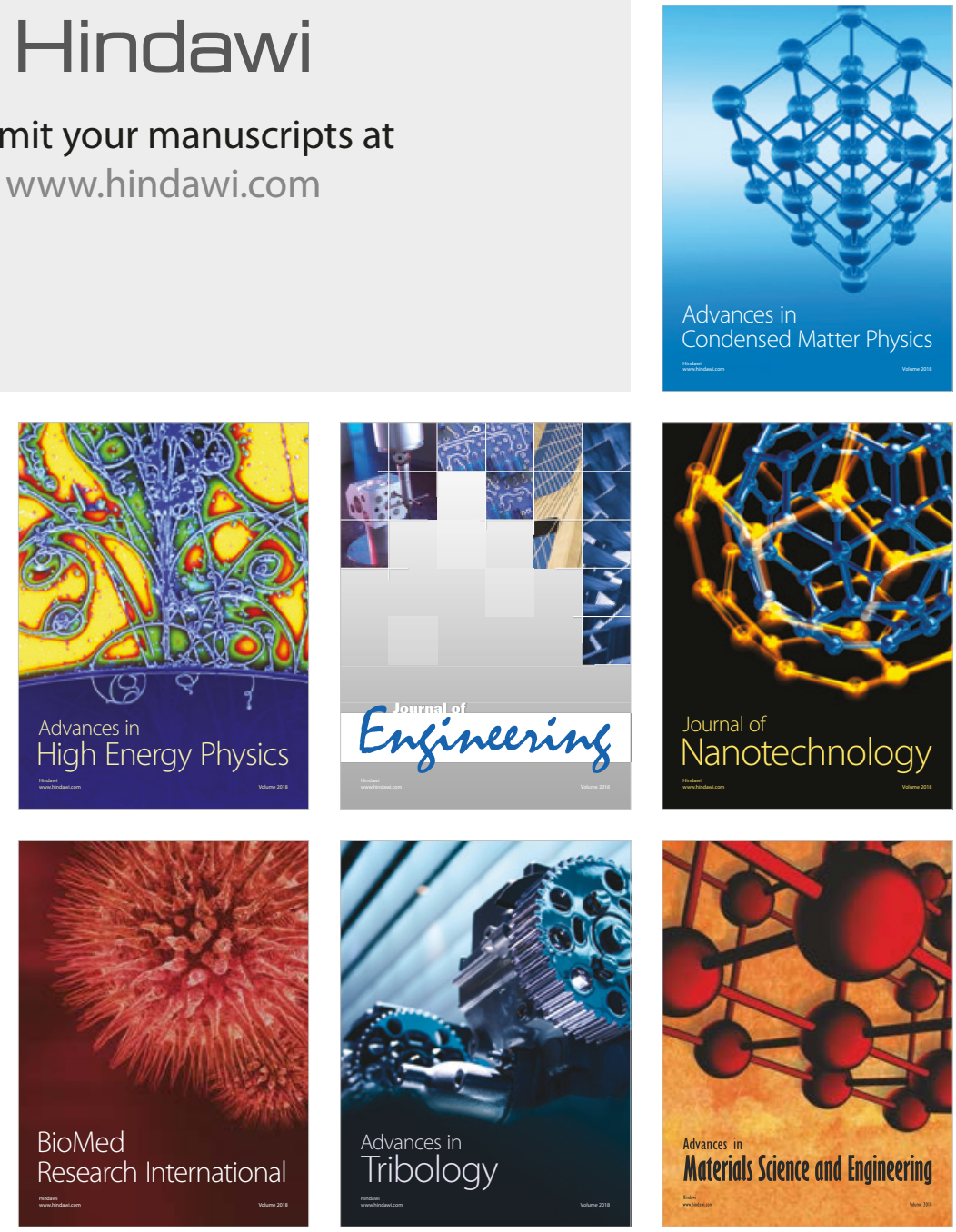